\title{
Experimental investigation of air bubble/packing humidifier for desalination system driven by solar energy
}

\author{
K. Elsawy ${ }^{1}$, I.A.Ibrahim ${ }^{2}$, A. Abdelmotalip ${ }^{3}$, Y. Elhenawy ${ }^{4}$ \\ ${ }^{1,}$ Mechanical Power Engineering Department, Port-Said University, Egypt,42523,karim_elsawy2007@yahoo.com \\ ${ }^{2,}$ Mechanical Power Engineering Department, Port-Said University, Egypt,42523,eng.hema@eng.psu.edu.eg \\ ${ }^{3,}$ Mechanical Power Engineering Department, Port-Said University, Egypt,42523,Abdelhadyelabady@gmail.com \\ ${ }^{4,}$ Mechanical Power Engineering Department, Port-Said University, Egypt,42523,dr_yasser@eng.psu.edu.eg
}

\begin{abstract}
In this paper, two systems based on the humidification dehumidification process driven by solar energy were examined. The first system uses a humidifier of the packing type (HPT), while the second system uses a humidifier of the air bubble column type ( temperature, air temperature, water level, air level, and velocity of air were experimentally investigated. It is demonstrated that there is optimum mass ratio obtained to get the maximum water productivity. Moreover, in the HBCT system, there is a maximum value of water level inside the column and also the optimum value of air velocity to get the maximum freshwater productivity. The two systems HPT and HBCT were examined by using the solar collector as a heating source for the saline feed water and the introduced air to the humidifier, and it is found that the freshwater productivity was $8.53 \mathrm{~kg} /$ day and $5.04 \mathrm{~kg} /$ day for HPT and HBCT systems with a cost of US $\$ 17.07 / \mathrm{m}^{3}$ and to reduce the carbon dioxide released by $4534 \mathrm{~g} /$ day. The results of performance and the economic analysis of the proposed system are comparable to those published for other similar solar desalination systems.
\end{abstract}

Key words:Humidification dehumidification, Packing, Air bubble column, Solar energy, Desalination.

\section{INTRODUCTION}

The world in the future confront energy deficiency and freshwater. Both of them are important in the development of any nation. Desalination of brackish or seawater is one of the most important ways to settle the water scarcity issue in the world. A small size water desalination method is a solution to reproduction fresh water for teeny society. The utilize of solar energy or trash heat sources is suitable for such small size systems for produce water. Humidification dehumidification desalination $(\mathrm{HDH})$ method is appropriate method used in water desalination.

The effect of waste energy on HDH desalination system were discussed by Han et al [1]. The performance of the system was analyzed and the gained-output-ratio (GOR) was calculated.
By increasing the inlet feed temperature of the sea water side, the GOR and the final water production was increased. Deniz and Cinar [2] discussed the different factors affected the desalination process. They found that the most effective time period of HDH system is between 1:00 pm and 6:00 pm. Moreover, the cost of desalination by HDH systems decreases with increasing efficiency. By increasing the temperatures of water and air at the humidifier inlet, the productivity enhanced. A solar still (SS) incorporated with a solar humidification- dehumidification system is deliberated by EL-samadony et al [3]. The results showed that, solar still unit or HDH unit are not effective individually for desalination and recommended to integrate the SS unit with $\mathrm{HDH}$ unit to enhance the performance. Yildrim and Solmus [4] found that, the water production is affected by the inlet water temperature, while the inlet air temperature has a weak influence on the productivity. As the water and air flow rates the productivity increased. Thiel et al. [5] explained the influence of mass extractions and injection on the performance of a fixed-size HDH desalination system. It is inferred that, the most favorable extraction flow rate from the dehumidifier to the humidifier, of the total circuit flow, was about $40 \%$. EL-Shazly et al [6] investigated experimentally the effect of using pulsating liquid flow on the performance of $\mathrm{HDH}$ system. The hot seawater was driven through the humidification unit in pulsed flow regime counter current to a continuous airflow forced to the humidifier bottom. The investigated parameters are the pulsation frequency, the pulsation amplitude, the inlet water temperature, the inlet airflow rate and the cooling water flow rate. The best ratio on-off time is found to be 20:60 for enhancing the HDH unit performance and the productivity of water. Kabeel et al [7] examined factors affecting the performance enhancement of the HDH desalination unit by using forced and natural air circulation. Increasing the package area increases the distillate productivity, and the condenser of cylindrical shell and corrugate fins has a rate of heat transfer larger than a rectangular one. The water mass ratio of inlet condenser to hot water at evaporator which gives a maximum productivity should be twice. Li et al. [8] used a $\mathrm{HDH}$ process of solar air collector with evacuated tubes. By increasing the temperature of the sprayed water, the humidity improved and the outlet air temperature of humidifier increased. The productivity is improved by using solar air heater collector under the same cooling conditions and air flow rate. Sharqawy et al [9] 
analyzed the main design and performance parameters for different cycles. For water-heated cycle, the proper mass flow rate is always greater than one and is always less than one for air-heated cycle. The GOR increased as the humidifier effectiveness increased.

A desalination system using four solar stills and HDH system was established by Kabeel et al. [10]. The fresh water production by the hybrid system was increased compared to the fresh water productivity from solar stills. He et al. [11] analysed theoretically novel cogeneration power desalination plant based on the HDH processes associated with the organic Rankin cycle. The hot concentrated brine from the HDH unit is used to heat the working medium in the Rankin cycle to the desired operating points to produce electricity. They showed that the demand of electricity and fresh water can be obtained from that novelplant. Mohamed and El-Minshawy [12 and 13] theoretically investigated a $\mathrm{HDH}$ desalination system integrated with a parabolic trough collector and a HDH system using the geothermal energy by using a simulation model. The used solar collector can produce outlet temperatures less than $100{ }^{\circ} \mathrm{C}$ to operate the suggested $\mathrm{HDH}$ desalination system. For the geothermal energy system, the peak ratio of seawater flow rate to air ratio was found between 1.5 to 2.5. Another novel method is used recently in HDH desalination system by using air bubble column. Pirdashti and Kompany [14] investigated the height to diameter $(\mathrm{H} / \mathrm{D})$ ratio in a bubble column. The $H / D$ ratio is investigated on the bubble holdup values and the results showed that, the effect of $\mathrm{H} / \mathrm{D}$ ratio is negligible. The results indicated that, an elevation in $\mathrm{H} / \mathrm{D}$ ratio leads to an increase in the axial dispersion coefficient. Pourtousi et al. [15] investigated numerically the effect of ring sparger diameter in bubble column on hydrodynamics by using CFD model. It is indicated that, the coalescence of bubbles appears towards the column center. At the middle size ring sparger, the gas holdup and the axial liquid velocity of the center decreases. In the larger ring sparger diameter, the bubbles coalescence rarely occurs near the sparger region. Shahid and Pashley [16] examined the effects of high bubble temperatures on the evaporation efficiency of distilled and salt water. The results indicated that, using high bubble temperature or high inlet gas temperatures and using adsorbed surfactant monolayers increase the effective super saturation and increase the water vapor carry over rate. A. Khalil et al. [17] used an air bubble column humidifier in a solar desalination system. The influence of different operating parameters on the desalination process was studied. The results showed that, the efficiency, productivity and GOR are affected by water temperature and airflow rate to the humidifier. Increasing water height increased slightly the productivity. Finally, the study proved that the air bubble column humidifier achieved a higher performance than that for the conventional one.

Based on the previous studies, the present work is aiming to make a comparison between a vertical air bubble column humidifier, with multi pipes, and a packing humidifier. The recent research is discussing the variable parameters affecting the water productivity for both systems.

\section{EXPERIMENTAL SETUP}

A solar desalination unit based on a humidification and dehumidification process was designed and constructed. The cycle is equipped, mainly, by $\mathrm{V}$-groove air collector, a flat plate water collector, a humidifier and a condenser. In present work, the brine heater is a flat plate solar collector. The solar water collector is $1 \mathrm{~m}$ wide, $2 \mathrm{~m}$ long and $0.15 \mathrm{~m}$ high with a surface angle of $30^{\circ}$. The solar air collector is $1.15 \mathrm{~m}$ wide, $2.3 \mathrm{~m}$ long and $0.25 \mathrm{~m}$ high and placed at a surface angle of $30^{\circ}$. The dehumidifier consists of a PVC pipe with a length of $75 \mathrm{~cm}$ and a diameter of $22 \mathrm{~cm}$. A copper helical coil is used inside the PVC pipe to cool the humid hot air and condensate the water vapor to obtain fresh water. A cold water is obtained from the cooling tank (2000 liter) by using a centrifugal pump to be introduced inside the helical coil. A humidifier is a device used to humidify the hot air by using the hot saltwater. Two configurations of humidifiers were used: a humidifier using a packing, the same idea of cooling tower, and an air bubble column, as shown in Figure1 and Figure2.

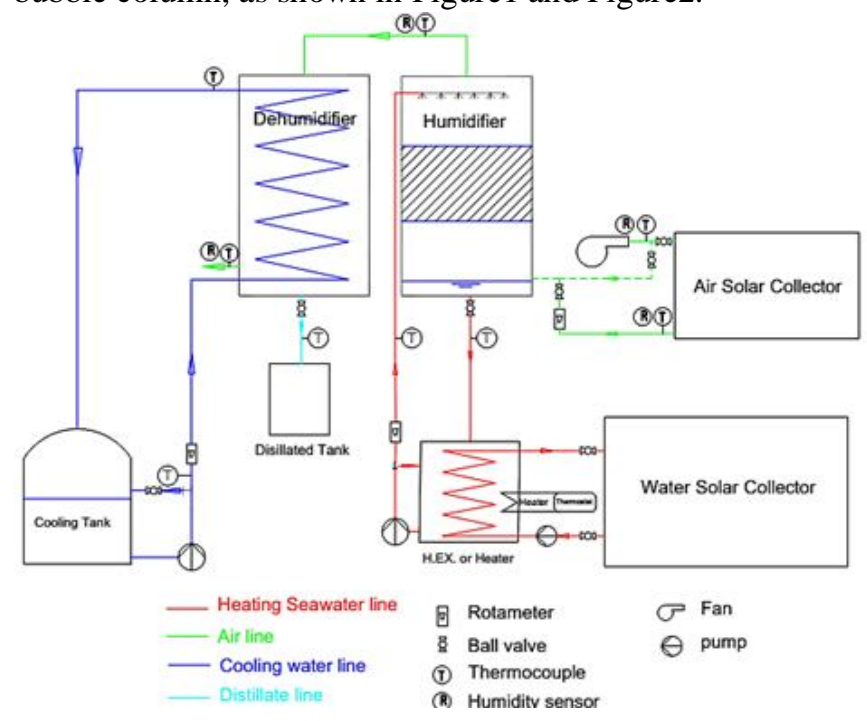

Figure 1:Flow diagram of HPT.

In the HPT configuration saltwater, on the one hand, is heated by an electrical heater (for steady state conditions) or a solar water collector, on the other hand, saltwater is sprayed by a sprinkler to form a falling film at the surface of the UPVC wall in the humidifier shown in Fig 3. The air is heated by a solar air collector. Moreover, the air is forced to pass through the humidifier where it is heated and humidified as a result of exchange heat and mass between the saltwater and air. Then, the humidified air is cooled by the cooling water when passing through the condenser at which the water vapor condenses into fresh water. The condenser is a one shell and helical tube type. The cooling water flows inside the tube and the fresh water is produced from the condensate on the permitted tube surface. 


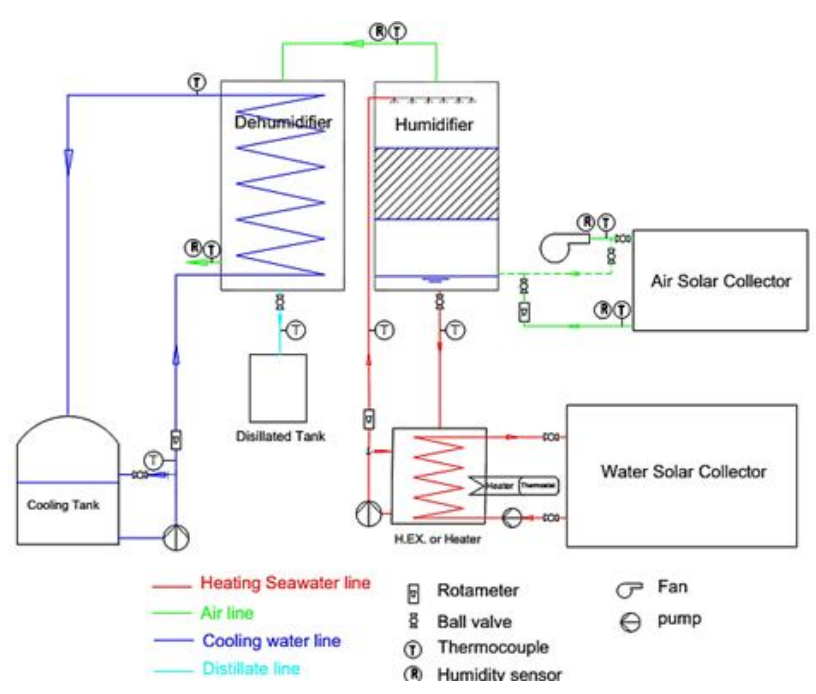

Figure 2:Flow diagram of HBCT.

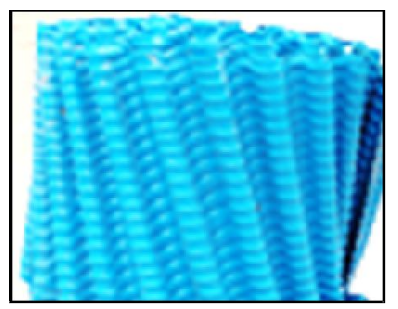

Figure 3:UPVC packing.

The saltwater, in the HBCT configuration, is heated by an electrical heater (for steady state conditions) or a solar water collector and then introduced to the UPVC column with perforated pipes. The hot air is introduced firstly through the perforated pipes inside the column, then after that the hot saltwater is introduced inside the column to form air bubbles. Those bubbles are good media for mass and heat transfer. The hot humid air bubbles are cooled by the cooling water when passing through the condenser like the HPT configuration. A Photograph of test rig is given in Fig 4.

The humidifiers used in this study were two types, the packing humidifier and the air bubble column as shown in Figure5 and Figure6.The packing humidifier is a counter flow packed type. Water is sprayed over the packing which helps to increase the mass and heat transfer contact area between the sprayed water and the forced air.
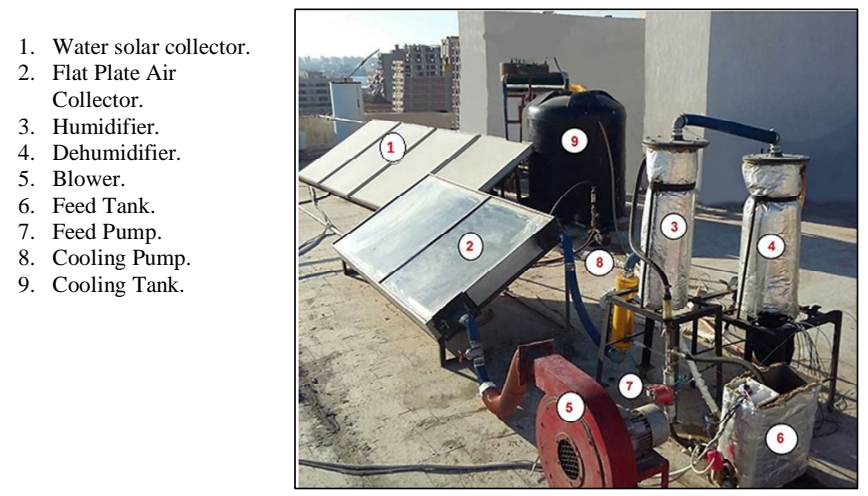

Figure 4:A Photograph of test rig.
The air which flows from bottom to top is heated and humidified while the sprayed water is cooled. The packed humidifier used in this study consists of a PVC pipe with a length of $75 \mathrm{~cm}$ and a diameter of $21 \mathrm{~cm}$. At the top of the pipe, there is a liquid sprayer, where the water is sprayed by using feed pump. At the bottom there is a brine collecting tank, where the water is collected as it drains down the packing. At the bottom of the pipe, the air is forced inside the pipe by air blower. The packing used inside the pipe is a corrugated PVC sheet with a diameter of $21 \mathrm{~cm}$.

The HBCT is air bubble column with shell and tube, the shell is a UPVC pipe that is $80 \mathrm{~cm}$ in length and 8 -inch diameter. There are 4 tubes open from bottom for air flow and closed from top, each one is 1-inch diameter and $115 \mathrm{~cm}$ in length, each tube has 160 holes those are $1.5 \mathrm{~mm}$ in diameter each and are divided in 4 columns across the $60 \mathrm{~cm}$ of tube length. The number of holes allow air flow is adjustable using inner hoses. Each tube center is located at $5 \mathrm{~cm}$ from the center of the shell and the distance between each two tubes is $10 \mathrm{~cm}$. There are two opposite transparent $0.03 \mathrm{~cm}$ thickness polycarbonate sheets $30 \mathrm{~cm} * 15 \mathrm{~cm}$ fixed with 8 bolts and adjoined to the shell body with silicon. The shell is closed from top and from bottom with two $0.5 \mathrm{~cm}$ thickness nontransparent polycarbonate sheets fixed with chloroform. The inlet hole of water is 0.5 inch in diameter and the exit is 1 inch with flow control valve. The exit hole of humidified air is 1 inch in diameter.

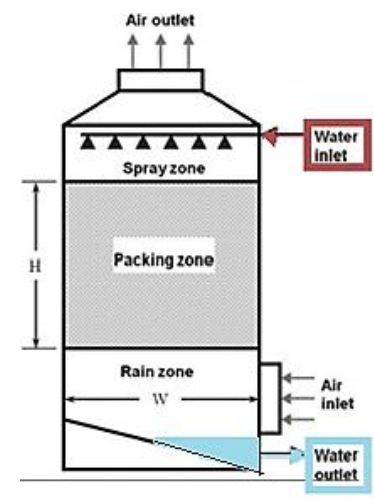

Figure 5:Packed humidifier.

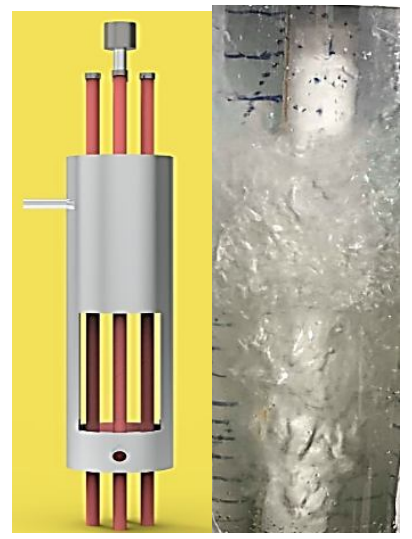
(a) 3D assembly
(b) Actual photo

Figure 6: Air bubble column humidifier. 


\section{MEASURING INSTRUMENTS}

During the experimental measurements of the $\mathrm{HDH}$ performance, the pressure is measured by a Dwyer 626-71-GHP9 pressure transmitter. A type T thermocouple are employed to measure the entrance and exit temperature of the different loops. The flow rates of the feed and the coolant are measured using an HFB-2-05 Dwyer rotameter. The feed water and the permeate salinity are measured by a CDHSD1(Omega) TDS meter. A digital balance measures the amount of distillate. The inlet airflow rate was tested by air rotameter KDG Houdec model 134/47 range of $(0-80) \mathrm{m} 3 / \mathrm{h}$ and a maximum temperature of $200^{\circ} \mathrm{C}$. All instrumentations were connected to the data acquisition system Midi LOGGER (GL820). The error in the pressure measurement is \pm 0.0072 bar, the error in the thermocouple reading is $\pm 0.104{ }^{\circ} \mathrm{C}$, while, the error in the flow rate measuring values is $\pm 0.05 \mathrm{~L} / \mathrm{min}$. The solar insulation received by the collector module surface was recorded by a CPM21 Pyranometer with a $0.0127 \mathrm{~W} / \mathrm{m}^{2}$ device accuracy.

\section{ANALYSIS OF UNCERTAINTY}

Normal uncertainties for instrumentation employed in the considered experimental setup are calculated using the below relation $[18,19,20]$ :

$$
u=x / \sqrt{3}
$$

where $\mathrm{x}$ denotes to instrument accuracy and standard uncertainty is u (see Table 1).

\section{EXPERIMENTAL RESULTS AND DISCUSSION}

Many parameters were tested to identify the water productivity and performance of the $\mathrm{HDH}$ desalination unit. The experimental runs were held on both the steady state system (electrical heater) and unsteady state system (solar energy). The investigated parameters are temperature, water-air mass ratio and salinity.

Table 1:Instruments accurateness and standard uncertainties

\begin{tabular}{|c|c|c|c|}
\hline Device & Accuracy & Range & $\begin{array}{c}\text { Standard } \\
\text { Uncertainty }\end{array}$ \\
\hline Pyranometer & $\begin{array}{l}0.022 \\
\mathrm{~W} / \mathrm{m}^{2}\end{array}$ & $0-2000 \mathrm{~W} / \mathrm{m}^{2}$ & $\begin{array}{c}12.70 \times 10^{-3} \\
\mathrm{~W} / \mathrm{m}^{2}\end{array}$ \\
\hline Thermocouple & $0.18^{\circ} \mathrm{C}$ & $0-150{ }^{\circ} \mathrm{C}$ & $10.40 \times 10^{-2}{ }^{\circ} \mathrm{C}$ \\
\hline Rotameter & $0.1 \mathrm{~L} / \mathrm{min}$ & $10 \mathrm{~L} / \mathrm{min}$ & $0.05 \mathrm{~L} / \mathrm{min}$ \\
\hline Pressure & 0.0125 bar & $0-2.5$ bar & $7.2 \times 10^{-3} \mathrm{bar}$ \\
\hline Balance & $0.5 \mathrm{~g}$ & 1 to $25000 \mathrm{~g}$ & $0.289 \mathrm{~g}$ \\
\hline
\end{tabular}

\subsection{Effect of Using HPT on HDH System under Steady State Conditions}

The first group of experimental runs were held at different temperatures, different air flowrates, constant cooling water flowrate and constant feed water flowrate. The second group of experimental runs were held at different temperatures, variable feed water flowrates, constant cooling water flowrate and constant air flowrate.

Figure 7 shows the influence of mass ratio on freshwater productivity at variable feed water temperatures and at constant feed water flowrate. It is inferred that, productivity increases with increasing the feed water temperature and decreasing the mass ratio $[1,3]$. The maximum productivity was gained at $60^{\circ} \mathrm{C}$, mass ratio $=3$, and the lowest productivity was gained at $40^{\circ} \mathrm{C}$, mass ratio $=6$. The productivity at mass ratio $=3$ is increased by about $57 \%$ as the feed water temperature elevated from $40^{\circ} \mathrm{C}$ to $50^{\circ} \mathrm{C}$, while the productivity is increased by about $250 \%$ when the feed water temperature increased from $40^{\circ} \mathrm{C}$ to $60^{\circ} \mathrm{C}$. This can be attributed to the bonding connections between hot salt water molecules become weaker at the higher temperatures. Therefore, the introduced air from the blower can carry the vapor from the hot saline water easily. The maximum productivity is found at the lowest mass ratio also. This is attributed to the air flowrate is at the peak value, so this high air flowrate is able to carry much vapor from the hot salt water.

Figure 8 shows the effect of mass ratio on fresh water productivity at variable feed water temperatures and at constant air flowrate. It can be seen that, water productivity increases with either increasing the feed water temperature or with increasing the mass ratio. The maximum productivity was gained at $60^{\circ} \mathrm{C}$, mass ratio $=5$ and the lowest productivity was gained at $40^{\circ} \mathrm{C}$, mass ratio $=2$. The productivity at mass ratio $=5$ is increased by about $10 \%$ when the feed water temperature increased from $40^{\circ} \mathrm{C}$ to $50^{\circ} \mathrm{C}$, while the productivity is increased by about $137 \%$ when the feed water temperature increased from $40^{\circ} \mathrm{C}$ to $60^{\circ} \mathrm{C}$. This is can be attributed to the bonding connections between hot saltwater molecules get weak at the higher temperatures, so the introduced air can carry the vapor from the hot saltwater easily. The maximum productivity can be gained at the maximum mass ratio, as well. As the water-air mass ratio increased, the air flowrate is constant and the hot saltwater flowrate increased, so the hot saltwater flowrate is able to humid the air.

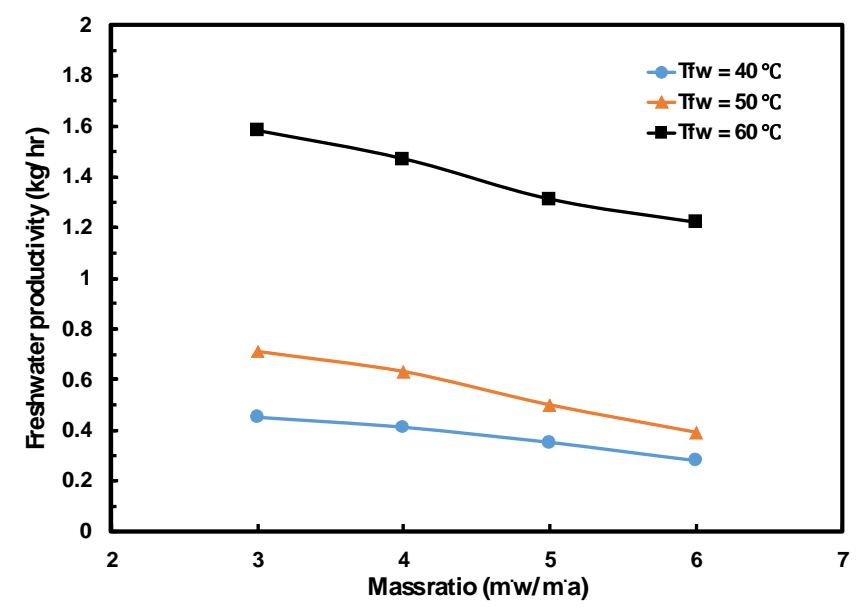

Figure 7:Effects of variable air flow rate on freshwater productivity at a different feed water temperature. 


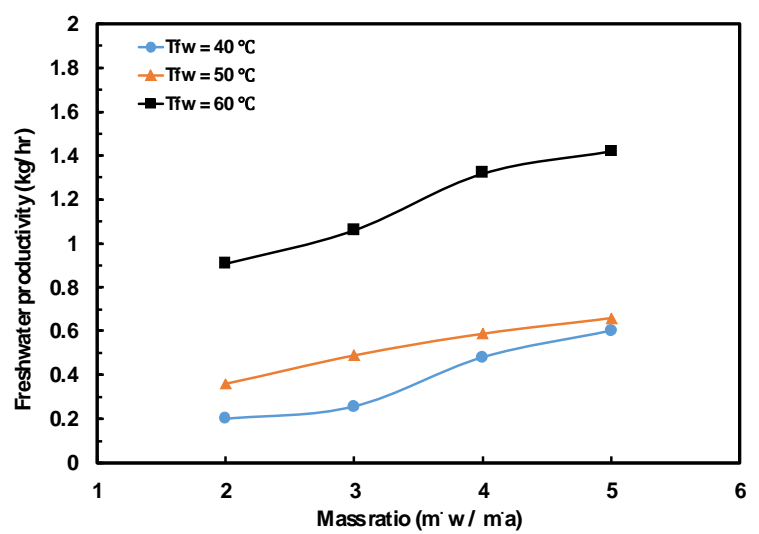

Figure 8:Effects of variable water flow rate on freshwater productivity at a different feed water temperature.

\subsection{Effect of Using PHT on HDH System under Unsteady State Conditions}

In this system, the experiments were implemented by using the solar energy. From the previous system (steady state system), the examined conditions used to get the best results for packing system, by using the electrical heater, were used again to examine the performance of $\mathrm{HDH}$ desalination unit by using the solar energy. For packing system, Figure9 shows the solar irradiation in Port Said at $27^{\text {th }}$ of June 2018 from 10:00 am to $5: 00 \mathrm{pm}$ and the productivity of fresh water produced from heating both the brine water and the ambient air by using the packing humidifier. Distillate of the system augments with the time and rises till noon due to the increase in solar radiation. The freshwater productivity from the system is $8.53 \mathrm{~kg} /$ day. Figure 10 shows the temperature distribution for whole system. It is shown that, temperatures increase and decrease with increasing and decreasing solar radiation, respectively. The best results at steady state system were obtained at the feed brine water of $3.1 \mathrm{~L} / \mathrm{min}$ at $60^{\circ} \mathrm{C}$, air flowrate of $52 \mathrm{~m}^{3} / \mathrm{h}$ and cooling water flowrate of $4.6 \mathrm{~L} / \mathrm{min}$. Those conditions were used again in the unsteady state system to examine the performance of the HDH desalination unit by using the packing humidifier.

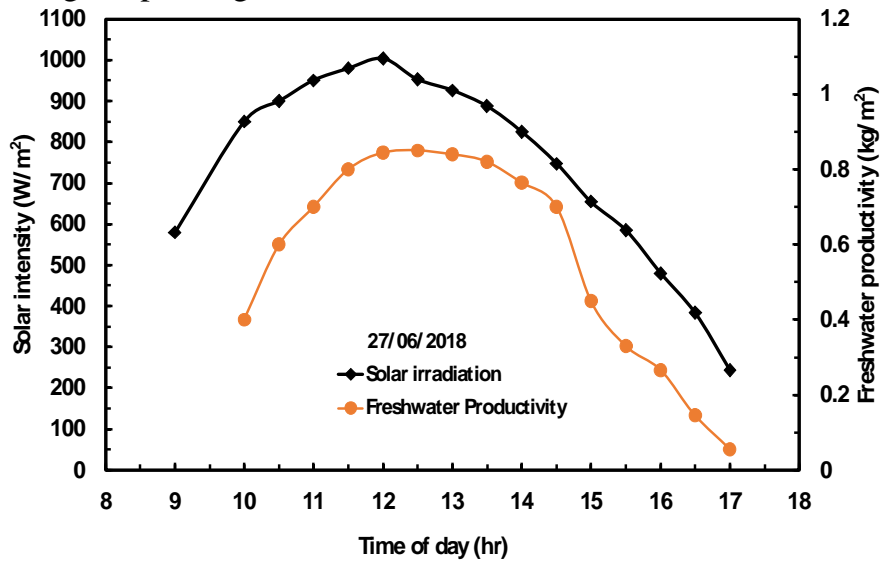

Figure 9:Hourly variation in the average solar irradiance versus freshwater productivity.

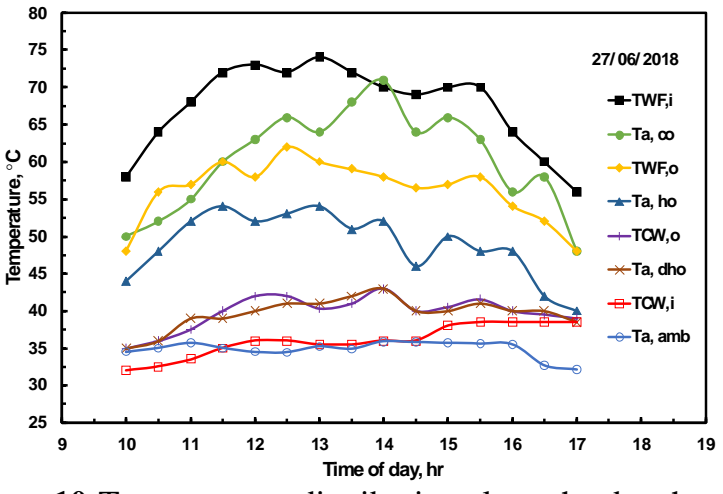

Figure 10:Temperatures distribution along the day through the HDH system.

\subsection{Effect of Using HBCT on HDH System under Unsteady State Conditions}

In this type of humidifier, the experimental runs were conducted at the optimum conditions used in the experimental runs of packing type humidifier, where the air flow rate is 52 $\mathrm{m}^{3} / \mathrm{h}$, saline feed water flowrate is $3.1 \mathrm{~L} / \mathrm{min}$ and the temperature of saline water is $60^{\circ} \mathrm{C}$. Some parameters were investigated to determine their influence on the fresh water productivity. Increasing or decreasing water head in air bubble column was examined on desalinated water productivity. In addition, the number of tubes, which were variable by blocking the path of air in some of them, were investigated, as well. The number of air holes has also great effects on water productivity, and they were controlled by internal core which blocks some air holes.

Figure 11 shows the fresh water productivity at different water depth, different number of tubes, constant air depth and constant volume flow rate for air and for water. The results indicated that, the freshwater productivity and the water depth increased by decreasing the number of tubes. The fresh water productivity increased with increasing water depth. In addition, it can be seen that the best heat and mass transfer occurs in case of a single tube. In the case of a single tube, the air velocity increases compared with the other cases. For the case of a single tube, three experiments were implemented at constant air flowrate, constant water flowrate, constant water depth and variable air depth. The results of those experiments showed that, there is a range of air velocities, which achieves the best heat and mass transfer [21,22] as shown in Figure.12.

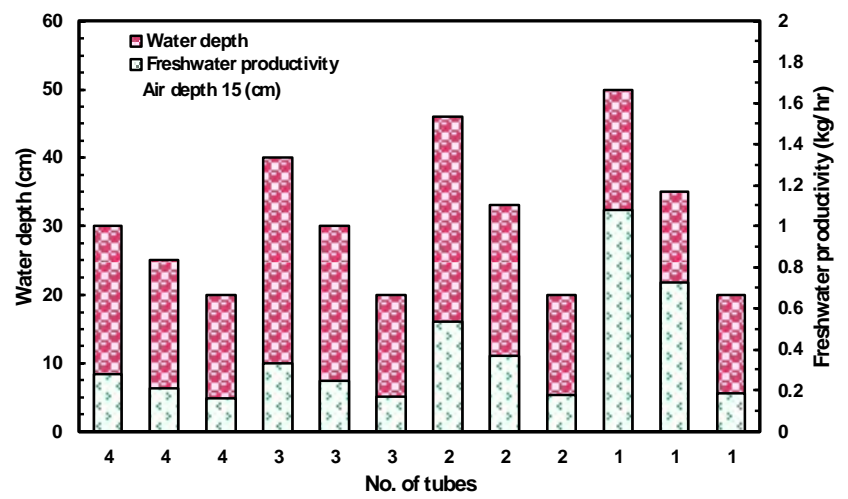

Figure 11:Fresh water productivity at different water depth, number of tubes, constant air depth and constant flow rates. 


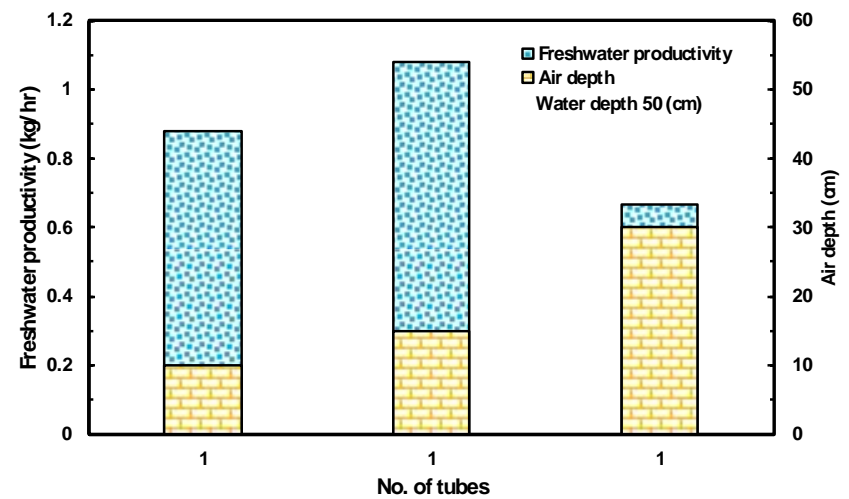

Figure12: Fresh water productivity at different air depth, constant water depth and constant volume flow rate for air and water for one tube.

The relation between the difference in temperature between the inlet and the outlet feed water $\Delta T_{f, w}$ and water depth, at constant air depth and constant volume flow rate for air and water, for a single pipe is shown in Figure 13. For the highest water depth of $50 \mathrm{~cm}$, the best heat and mass transfer occurs and the highest water productivity is gained. If the water depth increased above $50 \mathrm{~cm}$, the air pressure dropped and the air pipe filled with water and, hence, the water productivity decreased. The water depth has a clear effect on water productivity as mentioned in previous studies [23].

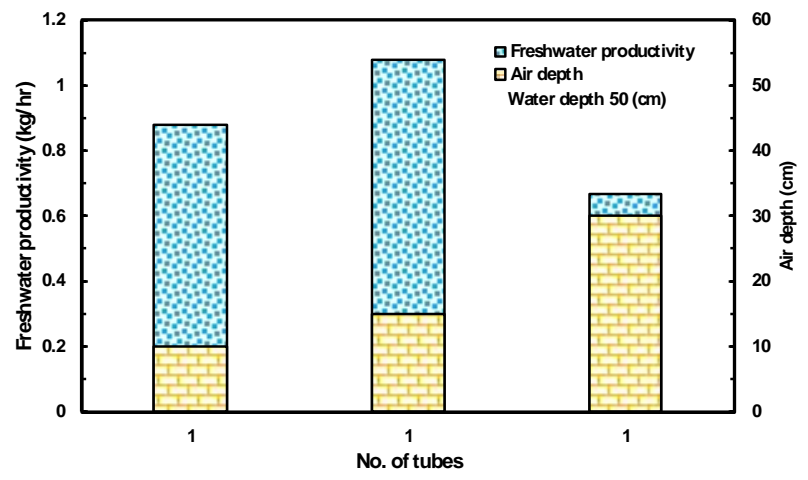

Figure13: $\Delta T_{f . w}$ and water depth at constant $\theta$ and volume flow rate for air and water for one tube.

\subsection{Effect of Using HBCT on HDH System under Unsteady State Conditions}

In this experimental run, it was supposed to use the same conditions used in the previous experimental runs which held under unsteady state conditions using the packing type humidifier. The air flowrate, the saline water flowrate and the cooling water flowrate of $52 \mathrm{~m}^{3} / \mathrm{h}, 3.1 \mathrm{~L} / \mathrm{min}$ and $4.6 \mathrm{~L} / \mathrm{min}$, respectively were used in packing humidifier. In the air bubble column humidifier, the air flowrate, the saline water flowrate and the cooling water flowrate were $25 \mathrm{~m}^{3} / \mathrm{h}, 3.1$ $\mathrm{L} / \mathrm{min}$ and $6 \mathrm{~L} / \mathrm{min}$ respectively. The reason that air flowrate decreased from $52 \mathrm{~m}^{3} / \mathrm{h}$ to $25 \mathrm{~m}^{3} / \mathrm{h}$ is that the blower could not reach to $52 \mathrm{~m}^{3} / \mathrm{h}$ because of the back pressure from inside of the tube. The reason of that back pressure is that when the air flows inside the pipe, it faces resistance from the water around air pipe and from the inside pipe surface, and as a result, the air returns back towards the blower. The maximum water depth was $25 \mathrm{~cm}$, although the maximum water depth achieved in steady state experiments was $50 \mathrm{~cm}$. the reason of that reduction in water depth is the air pressure from the blower is less than the air pressure from the compressor. Therefore, the air flowrate from blower can't withstand the pressure of water column. The maximum water depth can be achieved and does not fill the air pipe is $25 \mathrm{~cm}$. Figure 14 shows the solar radiation in port said at $6^{\text {th }}$ of July, 2018 from 10:00 am to 5:00 pm and the productivity of desalinated water produced from heating both the brine water and ambient air by using the air bubble column humidifier. Fresh water of the system raises with the time and rises till noon due to the increase in solar radiation. The fresh water productivity from the system is $5.04 \mathrm{Kg} / \mathrm{day}$. Figure 15 shows the temperature distribution for whole system. Temperatures increase and decrease with increasing and decreasing solar radiation, respectively.

By comparing the results between the two experiments (heating ambient air and saline water) with using two humidifiers (HPT and HBCT) using solar energy, it is indicated that, the productivity from experiment using HPT is better than the productivity from the experiment using HBCT.

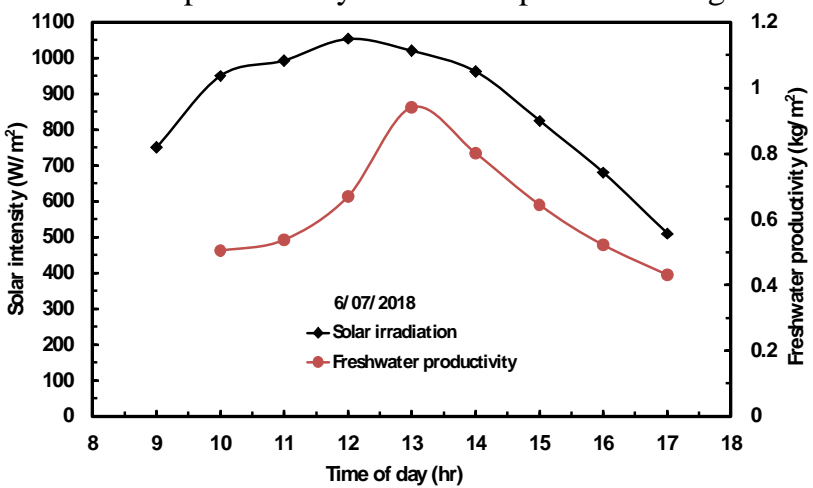

Figure14:Hourly variation in the average solar irradiance versus freshwater productivity.

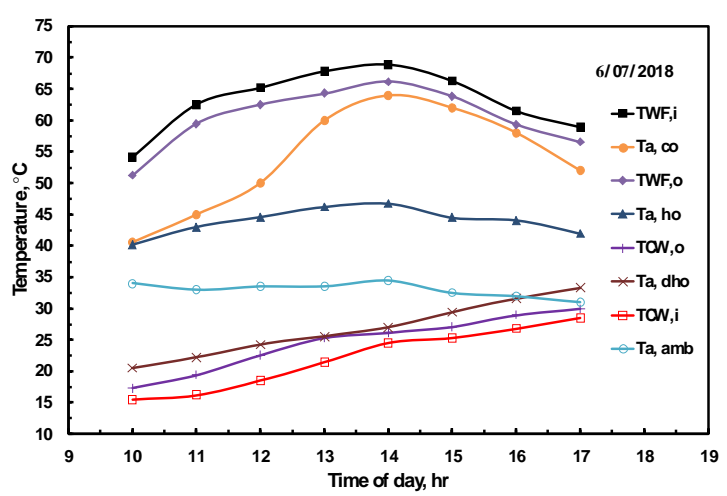

Figure15:Temperatures distribution along the day through the HDH system.

\subsection{Thermal Performance of HDH System}

In HDH configurations, another factor is considered for assessing the thermal performance of $\mathrm{HDH}$ system, explicitly the GOR, that links heat consumed to generate freshwater productivity to the sum of thermal energy provide outwardly [24,25].

$\mathrm{GOR}=\mathrm{m}_{\mathrm{p}} \times \mathrm{H}_{\mathrm{v}} / \mathrm{Q}_{\mathrm{TE}}$ 
$\mathrm{H}_{\mathrm{v}}$ is estimated by [26,27]:

$\mathrm{H}_{\mathrm{v}}=2501.897149-2.407064037 \times \mathrm{T}+0.001192217 \times \mathrm{T}^{2}-$ $0.000015863 \times \mathrm{T}^{3}$

where $\mathrm{T}$ is the temperature at the humidifier entrance and exit $\left({ }^{\circ} \mathrm{C}\right)$.

The thermal energy supplied was evaluated as:

$\mathrm{Q}_{\mathrm{TE}}=\mathrm{m}_{\mathrm{f}} \times \mathrm{C}_{\mathrm{p}} \times\left(\mathrm{T}_{\mathrm{h}, \mathrm{i}}-\mathrm{T}_{\mathrm{h}, \mathrm{o}}\right)$

wherem $_{\mathrm{f}}$ is the feed water flow rate $(\mathrm{kg} / \mathrm{h}), \mathrm{C}_{\mathrm{p}}$ is the feed water heat capacity $\left(\mathrm{kWh} / \mathrm{kg}{ }^{\circ} \mathrm{C}\right), \mathrm{T}_{\mathrm{h}, \mathrm{i}}$ is the humidifier inlet temperature $\left({ }^{\circ} \mathrm{C}\right)$ and $\mathrm{T}_{\mathrm{h}, \mathrm{o}}$ is the humidifier outlet temperature $\left({ }^{\circ} \mathrm{C}\right)$.

The main objective of the HDH operation is to produce a high quantity of freshwater with the lowest possible energy. The required energy was evaluated via the STEC $\left(\mathrm{kWhm}^{-3}\right)$, defined as the external heat needed to generate quantity of freshwater, expressed by the following relation between energy efficiency ratio $\mathrm{Q}_{\mathrm{TE}}$ and the freshwater flow rate $\left(\mathrm{V}_{\mathrm{P}}\right)$ $[24,28]$.

$$
\mathrm{STEC}=\mathrm{Q}_{\mathrm{TE}} / \mathrm{Vp}
$$

The values of the thermal performance of the pilot $\mathrm{HDH}$ system through GOR and STEC for the studied HDH system were evaluated and plotted in Figure.16 and 17. Figure 16 illustrates the hourly gained output ratio (GOR) from the HDH system with HPT and HBCT units. Tests were performed from 10:00 AM to 5:00 PM with a feeding hot water flow rate of $3 \mathrm{~L} / \mathrm{min}$, coolant average temperature of 32 ${ }^{\circ} \mathrm{C}$ during the test day. As shown in the figure for the tested hourly, GOR rises considerably until the noontime and then decreases from that time till the end of the test day, with the maximum GOR of the HPT unit staying one hour ahead of the HBCT unit. The daily relative enhancement of the GOR by the HPT unit in comparison with the HBCT unit is about $41.07 \%$ for the feed airflow rate of $52 \mathrm{~m}^{3} / \mathrm{h}$. Figure 17 illustratesthe hourly STEC values for the HDH system with HPT and HBCT units. The results of the current study show that the STEC is low at the beginning of the test day and reaches its maximum vlaue at the noontime with the HPT unit. In contrast to the STEC of the HPT unit, the STEC value of the HBCT unit was decreased considerably until the noontime to be $0.7 \mathrm{kWh} /$ liter.

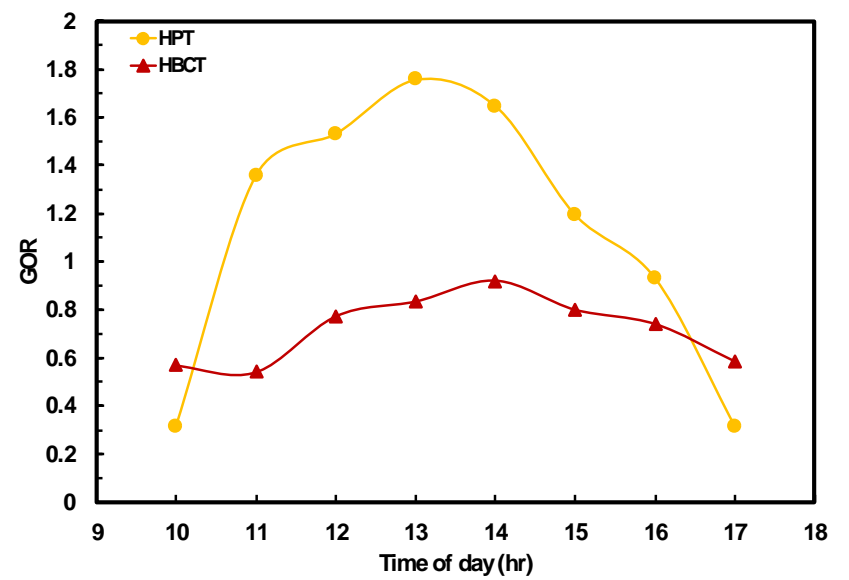

Figure16:Average hourly gain output ratio recorded during test sunny days.

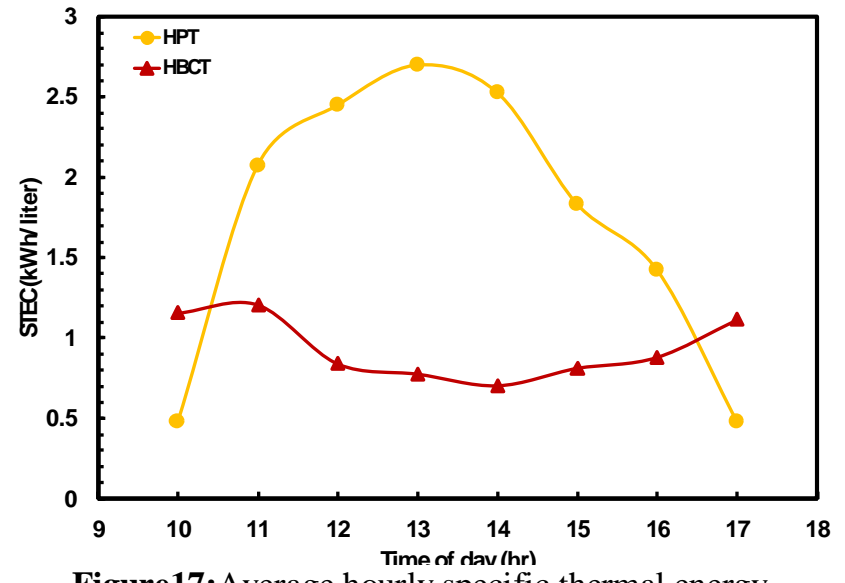

Figure17:Average hourly specific thermal energy consumption recorded during test sunny days.

\subsection{Mitigation Potential of $\mathrm{Co}_{2}$ Emissions}

Fossil fuel power stations seriously contribute to the problem of global $\mathrm{CO}_{2}$ emissions. This severe environmental problem requires urgent attention and, therefore, can be relatively tackled by expanding the use of renewable sources of energy including solar energy as a clean energy source to reduce the $\mathrm{CO} 2$ emission [29]. An additional benefit of implementing the CPV technology, besides sustainability, is its cleanness. Moreover, HDH systems, which utilize FPC for water heating for desalination, offer a new sustainable trend for decreasing the reliance on grid electricity and, subsequently, highly participating in reducing carbon oxides emission levels. The reduction of $\mathrm{CO} 2$ release level utilizing the proposed $\mathrm{HDH}$ system is estimated as the following formula [30]:

$$
m_{t}=m_{e} x d E x t_{\text {life }}
$$

where $m_{t}$ is the reduction in the emission level of $\mathrm{CO}_{2}(\mathrm{~g})$ over its life cycle, $m_{e}$ is the average emission of $\mathrm{CO}_{2}(904$ $\mathrm{g} / \mathrm{kWh}$ )issuedfrom a coal fuel-driven power station [31], $d E$ $(\mathrm{kWh} /$ day) is the total energy saving per day of the proposed $\mathrm{HDH}$ system, and $t_{\text {life }}$ (day) is the economic lifespan of the $\mathrm{HDH}$ system, counted as 20 years [32].

Figure18 shows the accumulated solar intensity, the reduction in $\mathrm{CO}_{2}$ emissions, and, therefore, the freshwater productivity for various humidifier configurations on each day. This figure illustrates that the accumulated daily irradiance values for the two test days of June, $27^{\text {th }}$ and July, $6^{\text {th }} 2018$, were 11,951 $\mathrm{W} /$ day and $12,000 \mathrm{~W} /$ day, respectively, during the experiments with HPT and HBCT. Clearly, the daily accumulated production of fresh water is highly increased by use the HPT system. The peak of freshwater productivity achieved for this set of experiments at HPT system is 8565 $\mathrm{g}$ /day. Moreover, the reduction in $\mathrm{CO}_{2}$ emissions per day due to the utilization of the HBCT system is $4118 \mathrm{~g}$. These figures demonstrate the proportionality of the cut down in $\mathrm{CO}_{2}$ with the humidifier configuration, which is referred to as the increase in the freshwater productivity with theHBCT, as previously discussed. In the case of a HPT,the daily accumulated cut down of carbon dioxide $\mathrm{CO}_{2}$ as a result of employing the proposed HDH system reached a value of 4534 g. 


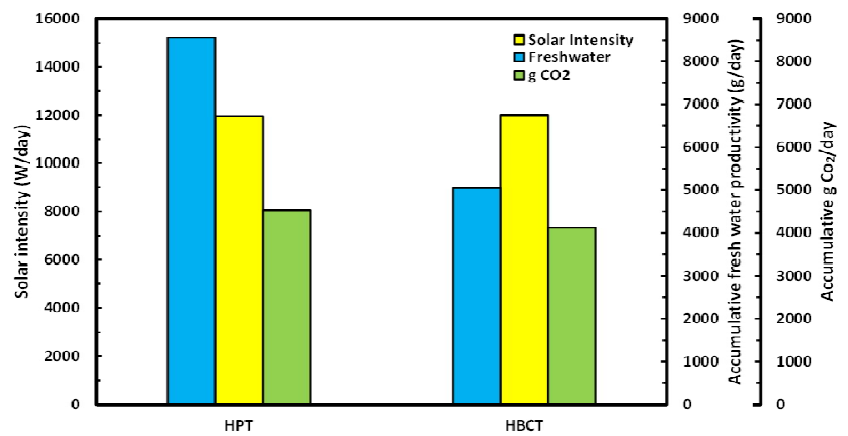

Figure 18: The daily accumulated solar intensity, accumulated daily potable water productivity and saving of $\mathrm{CO}_{2}$ against the humidifier configurations.

\section{ECONOMIC ANALYSIS}

The total cost of producing freshwater from the $\mathrm{HDH}$ system is mainly affected by both operational and capital expenditures. In this study, economic assessment is conducted using Levelized cost of water (LCOW) [ 33,34] as a reference method for assessing the cost-effectiveness of water produced from the HDH system. The LCOW deals with costs of determining the price per $\mathrm{m}^{3}$ of water production over the considered lifetime period. The detailed LCOW formulas used in the current work are given in Eqs. (7) to (11) taking into account the levelized cost of the investment LCinv (\$), the maintenance and operation expenditures LCO\&M (\$), and the running cost $(\mathrm{RC})$ of the powered components of system. The cost breakdown of the HDH system is illustrated in Table 2 . The cost of purifying one $\mathrm{m}^{3}$ of water LCOW $\left(\mathrm{US} \$ / \mathrm{m}^{3}\right)$ can be expressed as in Eq. (7) [34,35]:

$$
L C O W=\frac{L C_{i n v} \times C R F+L C_{O \& M}+R C-A S V}{V_{p}}
$$

Capital recovery factor referred as CRF represented in Eq. (8).

$$
C R F=\frac{i \times(1+i)^{n}}{(1+i)^{n}-1}
$$

Where $_{i}$ is the annual interest rate. The result of the salvage value (half of the reusable components) and Sinking Fund Factor (SFF) gives the Annual Salvage Value (ASV), which is formed as [36]:

$$
A S V=S F F \times L C_{i n v}
$$

Fund Factor (SFF) represented as:

$$
S F F=\frac{1}{(1+i)^{n}-1}
$$

Table 2: Cost breakdown of HD system.

\begin{tabular}{||l||c||}
\hline \hline Components & (HD) (\$) \\
\hline Humidifier & 25 \\
Dehumidifier & 50 \\
insulation, stand and constructions & 25 \\
Solar collectors for $1 \mathrm{~m}^{2}$ & 100 \\
Water pump & 50 \\
Blower & 50 \\
Piping, valves and tanks & 50 \\
\hline \hline
\end{tabular}

The annual average freshwater production by the proposed $\mathrm{HDH}$ system is estimated to be $3.12 \mathrm{~m}^{3}$. The initial investment cost of HDH system is 350 \$. The economic life of the HD system is 20 years and the annual rate of interest is $10 \%$. The capital recovery factor of about $11.74 \%$ was calculated by Eq. (3) and both costs of maintenance and operation are assumed to be $2 \%$ of the initial investment cost[37,38].

The annual operating costs of the water pump $\left(W_{p}\right)$ and the electrical water heaters $\left(W_{e l c}\right)$ of the proposed $\mathrm{HDH}$ system can be evaluated on the basis of the running cost provided by Siddiqui et al., [36,39]:

$$
R C=365 \times\left(W_{p} \times W_{\text {elc }}\right) \times \text { Time of day } \times \operatorname{Pr} \text { ice of } k W h
$$

where the cost of electricity is $0.019 \$$ per $\mathrm{kWh}$ [40] .It was estimated that the LCOW for the HDH system was $17.07\left(\$ / \mathrm{m}^{3}\right)$ or $0.017(\$ /$ liter $)$. A comparison is made in Table 3 between the present research, considering 20 years as economic life, and the work of Siddiqui et al., [36]. Table 3 shows that the combination of the HDH system with the heat recovery from the cooled $\mathrm{CPV}_{\mathrm{C}}$ module results in a marked decrease in the Levelized cost of water relative to other $\mathrm{HDH}$ systems.

Table 3: A levelized cost comparison with others.

\begin{tabular}{||c||c||c||}
\hline \hline \multirow{2}{*}{ Reference } & $\begin{array}{c}\text { n (economic life of } \\
\text { HD system), Year }\end{array}$ & LCOW, $\mathbf{( \$ / \mathbf { m } ^ { \mathbf { 3 } } )}$ \\
\hline Current study & 20 & 17.07 \\
{$[36]$} & 20 & 23.00 \\
\hline \hline
\end{tabular}

\section{CONCLUSION}

From the presented experimental results based on humidification and dehumidification, $\mathrm{HDH}$, the following conclusions can be obtained:

- $\quad$ The proposed HPT and HBCT systems have the capacity to produce fresh potable water of $8.53 \mathrm{~kg} /$ day and 5.04 $\mathrm{kg} /$ day, to cut down overall $\mathrm{CO}_{2}$ release by about $4534 \mathrm{~g}$ and $4118 \mathrm{~g}$ in the day, respectively.

- As the mass flow rate of water raised from 3 to $51 / \mathrm{m}$, the daily freshwater productivity decreased by $18.75 \%$ at maximum temperature $60 \square$ and constant airflow rate for the packing humidifier under steady-state conditions.

- maximum freshwater productivity occurs at configuration one pipe with $1.09 \mathrm{~kg} / \mathrm{h}$ for the air bubble column humidifier under steady-state conditions.

- The STEC value of the HBCT unit was decreased considerably until to be $0.7 \mathrm{kWh} /$ liter.

- The daily relative enhancement of the GOR by the HPT unit in comparison with the HBCT unit is about $41.07 \%$ for the feed airflow rate of $52 \mathrm{~m}^{3} / \mathrm{h}$.

- According to the economic evaluation using the LCE analysis, the cost of the cubic meter from the proposed $\mathrm{HDH}$ system reached $17.07 \$ / \mathrm{m}^{3}$ which is considered as a good figure compared to the cost of other systems in the previous studies.

- By comparing the results between the two experiments (heating ambient air and saline water) with using two humidifiers (packing type and air bubble column type) using solar radiation, it is indicated that the productivity from the experiment using packing type is better than the 
productivity from the experiment using air bubble type. The reason that the air bubble column humidifier is vertical and not horizontal like the other works. Also, in this recent work blower is used in air bubble column humidifier instead of the compressor as mentioned before in other works.

\section{ACKNOWLEDGEMENT}

The researchers would like to acknowledge the assistance given by Port-Said University for this study.

\section{NOMENCLATURE}

$A S V \quad$ Annual product salvage Value

$C_{p} \quad$ Heat capacity of the feed solution $\left(\mathrm{kJ} / \mathrm{kg}^{\circ} \mathrm{C}\right)$

$C R F$ Capital recovery factor

$d E \quad$ Total energy saving $(\mathrm{kWh})$

EC Electricity cost

$H_{v} \quad$ Latent heat of vaporization $(\mathrm{kJ} / \mathrm{kg})$

$i \quad$ Annual interest rate

$L C_{i n v}$ Investment cost (\$)

$L C_{O \& M}$ Operation and maintenance costs $(\$)$

$L C O W$ Levelized cost of water $\left(\$ / \mathrm{m}^{3}\right)$

$m_{e} \quad$ Average $\mathrm{CO}_{2}$ emissions $(904 \mathrm{~g} / \mathrm{kWh})$

$m_{f} \quad$ Feed flow rate $(\mathrm{kg} / \mathrm{h})$

$m_{p} \quad$ Freshwater flow rate $(\mathrm{kg} / \mathrm{h})$

$m_{t} \quad$ Total reduction of $\mathrm{CO}_{2}(\mathrm{~g})$

$n \quad$ Economiclife time (yr)

$Q_{T E}$ Thermal energy supplied (kWh)

SFF Sinking Fund Factor

STEC Specific thermal energy consumption $\left(\mathrm{kWh} / \mathrm{m}^{3}\right)$

$T_{\text {ho }} \quad$ Humidifier outlet temperature $\left({ }^{\circ} \mathrm{C}\right)$

$T_{h i} \quad$ Humidifier inlet temperature $\left({ }^{\circ} \mathrm{C}\right)$

$t_{\text {life }} \quad$ Economic lifespan

$u \quad$ Standard uncertainty

$V_{p}$ Volumetric freshwater flow rate produced $\left(\mathrm{m}^{3} / \mathrm{h}\right)$

$W_{\text {elc }}$ Annual running cost of electric water heaters ( $\left.\$ / \mathrm{yr}\right)$

$W_{p} \quad$ Annual running cost of water pump (\$/yr)

$x \quad$ Accuracy of device

\section{REFERENCES}

1. W. F. He, L. N. Xu and D. Han. Parametric analysis of an air - heated humidification - dehumidification (HDH) desalination system with waste heat recovery, Desalination, Vol. 398, PP.30-38, 2016.

2. E. Deniz and C. Serkan. Energy, Exergy, Economic and environmental (4E) analysis of a solar desalination system with humidification - dehumidification, Energy conversion and management, Vol. 126, PP. 12-19, 2016.

3. S. W. Sharshir, P., Y. Nuo, M. O. A. El-Samadony and A. E. Kabeel, A continuous desalination system using humidification - dehumidification and a solar still with an evacuated solar water heater, Applied thermal engineering, Vol. 104, PP. 734-742, 2016.

4. C.Yildrim and I. Solmus.A parametric study on a humidification - dehumidification (HDH) desalination unit powered by solar air and water heaters, Energy conversion and management, Vol. 86, PP. 568-575, 2014.

5. G. P. Thiel, J. A. Miller, S. M. Zubair and J. H. Lienhard, Effects of mass extraction and injections on the performance of a fixed - size humidification - dehumidification desalination system, Desalination, Vol. 314, PP. 50-58, 2013.

6. A. H. El-Shazly, A. A. AL-Zahrani, Y. A. Alhamed and S. A.Nosier. Productivity intensification of humidification - dehumidification desalination unit by using pulsed water flow regime, Desalination, Vol. 293, PP. 53-60, 2012.

7. A. E. Kabeel, M. H. Hamed, Z. M. Omara and S. W. Sharshir. Experimental study of a humidification dehumidification solar technique by natural and forced air circulation, Energy, Vol. 68, PP. 218-228, 2014.

8. X. Li, G. yuan, Z. wong, H. young li and Z. Xu. Experimental study on a humidification and dehumidification desalination system of solar air heater with evacuated tubes, Desalination, Vol. 351, PP. 1-8, 2014.

9. M. H. Sharqawy, M. A. Antar, S. M. Zubair and A. M. Elbashir. Optimum thermal design of humidification dehumidification desalination system, Desalination, Vol. 349, PP. 10-21, 2014.

10. S. W. Sharshir, G. Peng, N. Yang, M. A. Eltawil, M. K. A. Ali and A. E. Kabeel. A hybrid desalination system using humidification - dehumidification and solar stills integrated with evacuated solar water heater, Energy conversion and management, Vol. 124, PP. 287-296, 2016.

11. W. F. He, D. Han, L. N. Xu, C. Yue and W. H. Pu. Performance investigation of a novel water - power cogeneration plant (WPCP) based on humidification dehumidification (HDH) method, Energy conversion and management, Vol. 110, PP. 184-191, 2016.

12. A. M. I. Mohamed and N. A. El-Minshawy. Theoretical investigation of solar humidificationdehumidification desalination system using parabolic trough concentrators, Energy conversion and management, Vol. 52, PP. 3112-3119, 2011.

13. A. M. I. Mohamed and N. A. S. EL-Minshawy. Humidification - dehumidification desalination system driven by geothermal energy, Desalination, Vol. 249, PP. 602-608, 2009.

14. M. Pirdashti and R. Kompany. Effects of height to diameter ratio and aeration rate on liquid mixing and hydrodynamic properties in a bubble column, Iranian journal of chemical engineering, Vol. 6, No.3, 2009.

15. M. Pourtousi, P. Ganesan, S. C. Sandaran and J. N. Sahu. Effect of ring sparger diameters on hydrodynamics inbubble column: A numerical investigation, Journal of the Taiwan institute of chemical engineers 000, PP.1-11, 2016.

16. M. Shahid and R. M. Pashley. A study of the bubble column evaporator method for thermal desalination, Desalination, Vol. 351, PP. 236-242, 2014.

17. A. Khalil, S. A. EL-Agouz, Y. A. F. EL-Samadony and A. Abdo. Solar water desalination using an air bubble column humidifier, Desalination, Vol. 372, PP. 7-16, 2015.

18. S.Elhady, M.Bassyouni, R. A.Mansour, M. H.Elzahar, S.Abdel-Hamid, Y.Elhenawy, M. Y.Saleh. Oily Wastewater Treatment Using Polyamide Thin Film 
K. Elsawy et al., International Journal of Advanced Trends in Computer Science and Engineering, 9(5),September-October 2020,8737 - 8746

Composite

Technology. Membranes, Vol.10(5), PP. 84, 2020.

19. Y. Elhenawy, N. A. S. Elminshawy, M. Bassyouni, A. A. Alanezi and E. Drioli. Experimental and theoretical investigation of a new air gap membrane distillation module with a corrugated feed channel, J. Memb. Sci, Vol.594, PP. 117461, Jan 2020.

20. M. H. Abdel-Aziz, A. F. Al-Hossainy, A. Ibrahim, S. A. Abd El-Maksoud, M. Sh Zoromba, M. Bassyouni, S. M. S. Abdel-Hamid, A. A. I. Abd-Elmageed, I. A. Elsayed, and O. M. Alqahtani. Synthesis, characterization and optical properties of multi-walled carbon nanotubes/aniline-o-anthranilic acid copolymer nanocomposite thin films, Journal of Materials Science: Materials in Electronics 29, no. 19 (2018): 16702-16714.

21. N. G. Dean, R. F. Mudde, J. A. M. Kuipers, P. Peter Zehner and M. Matthias kiraume.Bubble columns, ULIMANN'S encyclopedia of industrial chemistry, Wiley-VCH Verlag Gmbh\&Co.KgaA, Weinheim, 2012.

22. N. Kantarci, F. Borak and K. O. Ulgen. Review bubble column reactors", Process biochemistry, Vol. 40, PP. 2263-2283, 2005.

23. K. Srithar and T. Rajaseenivasan. Performance analysis on a solar bubble column humidification dehumidification desalination system, Process safety and environmental protection, Vol. 105, PP. 41-50, 2017.

24. N. A. S. Elminshawy, M. A. Gadalla, M. Bassyouni, K. El-Nahhas, A. Elminshawy, Y. Elhenawy. A novel concentrated photovoltaic-driven membrane distillation hybrid system for the simultaneous production of electricity and potable water.Renewable Energy. Vol.162,PP. 802-817,2020.

25. S. Sagar, N. Iqbal, A. Maqsood, M. Shahid, N. A. Shah, T. Jamil, M. I. Bassyouni, Fabrication and thermal characteristics of functionalized carbon nanotubes impregnated polydimethylsiloxane nanocomposites. Journal of Composite Materials, 49(8), 995-1006, 2015.

26. A. N. Mabrouk, Y. Elhenawy, M. Abdelkader and M. Shatat. The impact of baffle orientation on the performance of the hollow fiber membrane distillation, Desalin. Water Treat., vol. 58, 2017.

27. M. Sh. S. Zoromba, Alghool, S. M. S. Abdel-Hamid, M. Bassyouni, M. H. Abdel-Aziz. Polymerization of aniline derivatives by $\mathrm{K} 2 \mathrm{Cr} 2 \mathrm{O} 7$ and production of $\mathrm{Cr} 2 \mathrm{O3}$ nanoparticles, Polymers for Advanced Technologies 28, no. 7 (2017): 842-848.

28. M. Bassyouni, I. Taha, Shereen M-S. Abdel-Hamid, Leif Steuernagel. Physico-mechanical properties of chemically treated polypropylene rice straw bio-composites, Journal of Reinforced Plastics and Composites 31, no. 5 (2012): 303-312.

29. Y. Mobarak, M. Bassyouni, M. Almutawa. Materials selection, synthesis, and dielectrical properties of PVC nanocomposites. Advances in Materials Science and Engineering, 2013.

30. N. A. S. Elminshawy, M. El-Ghandour, Y. Elhenawy, M. Bassyouni, D. G. El-Damhogi, and M. F. Addas. Experimental investigation of a V-trough PV concentrator integrated with a buried water heat exchanger cooling system,Sol. Energy, vol. 193, 2019.

31. I. li, O. A. Bamaga, L. Gzara, M. Bassyouni, M. H. Abdel-Aziz, M. F Soliman, M. Albeirutty. Assessment of blend PVDF membranes, and the effect of polymer concentrationand blend composition. Membranes, 8(1), $13,2018$.

32. S.M.S. Abdel-Hamid, O.A. Al-Qabandi, Elminshawy. N.A.S., M. Bassyouni, M.S. Zoromba, M.H. Abdel-Aziz, H. Mira, Y.Elhenawy. Fabrication and Characterization of Microcellular Polyurethane Sisal Biocomposites, Molecules, 24(24), 4585,2019.

33. A. A.Alanezi, M. R.Safaei, M. Goodarzi, Y. Elhenawy. The Effect of Inclination Angle and Reynolds Number on the Performance of a Direct Contact Membrane Distillation (DCMD) Process, Energies, 13(11), 2824,2020.

34. S. A. Sherif, M. A. Sadek, F. H. Ashour, M. Bassyouni. Effects of surface treatment of ground rice husk on the polyurethane based on castor oil. Polymers and Polymer Composites, 17(8), 481-485,2009.

35. Y. Elhenawy, G. Hafez, S. Abdel-Hamid and M. Elbany. Prediction and assessment of automated lifting system performance for multi-storey parking lots powered by solar energy, Journal of Cleaner Production, Vol. 266, 2020.

36. F. R. Siddiqui, N. A. S. Elminshawy and M. F. Addas. Design and performance improvement of a solar desalination system by using solar air heater: Experimental and theoretical approach, Desalination, Vol. 399, PP. 78-87, 2016.

37. N. A. Elminshawy, A. M. I. Mohamed, K. Morad, Y. Elhenawy and A. A. Alrobaian. Performance of PV panel coupled with geothermal air cooling system subjected to hot climatic,Applied Thermal Engineering,Vol. 148, PP. 1-9, 2019.

38. M. Tawarish, K. Satyanarayana. A review on pricing prediction on stock market by different techniques in the field of data mining and genetic algorithm.International Journal of Advanced Trends in Computer Science and Engineering,Vol.8, No.1, 23-26,2019.

39. V.Lyashenko, S. K.Mustafa, S.Sotnik, M. A. Ahmad. Basic Principles of Decision Making upon Receipt of New Nanomaterial, International Journal of Advanced Trends in Computer Science and EngineeringVol. 8, No.5,2019.

40. EEP,https://www.ceicdata.com/en/egypt/electricity-price/ electricity-price-residential-201350-kwh", (2018). 